\title{
LEADERSHIP UNITY AND ORGANISATIONAL COMPETITIVENESS IN DEPOSIT MONEY BANKS IN NIGERIAN
}

\author{
Margaret Diete-Spiff \\ Department of Management, Niger Delta University, Wilberforce Island, P.M.B 071, \\ Yenagoa,Bayelsa State, Nigeria. \\ Williams. O. Olori (PhD) \\ Department of Management, University of Port Harcourt Rivers State, Nigeria.
}

Article DOI: $\underline{\text { https://doi.org/10.36713/epra6477 }}$

\begin{abstract}
The paper is an empirical examination of the relationship between leadership unity and organizational competitiveness of deposit money banks in the south south geo-political zone of Nigeria. The research design was the cross-sectional survey and data was generated from 221 managers and supervisors from 18 deposit money banks in Rivers, Bayelsa, Cross River, Akwaibom, Edo and Delta States, using the questionnaire instrument. Reliability was established using the Cronbach alpha reliability test. The Spearman's rank order correlation was utilized in the test for the hypotheses of the study. Based on the results, all null hypotheses were rejected as the findings revealed that there exists a significant relationship between leadership unity and all measures of organizational competitiveness (innovativeness, service quality and delivery reliability) as used in the study. It was concluded that leadership unity offers cooperation and support in innovative actions and as such advances the competitiveness of the organization and leads to outcomes such as innovativeness, service quality and delivery reliability.
\end{abstract}

KEYWORDS; leadership unity, organisational competitiveness, innovativeness, service quality and delivery reliability.

\section{INTRODUCTION}

Over the years, the banking industry in Nigeria has been faced with a lot of restructuring and overhauling to enable more effective processes and better service delivery. The last bank consolidation by Soludo (the Central Bank of Nigeria Chairman) of 2004/5 caused the number of banks shrink from 89 t0 22. The stock market collapsed by seventy percent in 2008-2009 and many Nigerian banks had to be rescued. In order to stabilize the system and return confidence to the markets and investors, the Central Bank of Nigeria injected six hundred and twenty billion naira of liquidity into the banking sector and replaced the leadership at eight Nigerian banks (Sanusi, 2010). Ensuring this stability and continuous survival in the face of constant competition is a necessity for all banks to remain in business.

As a result of the business turbulence, organizations are finding it more difficult $o$ be competitive and ensure its survival. Ensuring efficiency and continuity of business operations is related to an understanding of the dynamics of the environment and the deployment of appropriate resources. Thus creating competitive capabilities in firms is primal to their survival. Monopoly in the provision of goods and services in the Nigerian economy by firms is a rarity as 
many sectors including banking is characterised by free entry and exit. Varying factors ranging from technological advancement, changing consumer preferences, economic downturn, and frequent change of government policies are plaguing the organizations of today. In addition to dealing with environmental turbulence, being innovative, having better service quality and ensuring delivery reliability are necessities for organizational competitiveness.

Strategic agility is a resource that can be employed by today's organisations to enable creation of more competitive organisations. According to the business dictionary, Strategic agility is the ability for companies to stay competitive in their business by adjusting and adapting to new innovative ideas and using these ideas to create new products and services as well as new business models. Being strategic evokes peering far into the future, making strong choices and holding firm commitments, unwavering deploying resources to implement them. In contrast, being agile evokes staying nimble and flexible, open to new evidences, always ready to assess past choices and change direction in the light of new developments, and willing and able to turn on a dime. Thus for organizations to be and stay competitive, they must constantly adjust courses of action and development trajectories, rather than being content with the periodic strategic reviews. The dimensions of strategic agility includes strategic sensitivity, leadership unity and resource fluidity. The work is streamlined to the role of leadership unity to organisational competitiveness.

Studies (Odja 2008; Mavengere 2013; Yusuf et al 2012) have shown that strategic agility has enhanced and sustained organisational competitiveness, but the intricacies and work place practices that enable a strategically agile organisation has been under studied. For example, it is believed that a unified leadership is key to having a strategically agile firm. Leadership unity ensures that top management are able to take ad implement adventurous but meaningful decisions and immediately implement them without tireless political negotiations. Ensuring leadership unity calls for safe experimentation. This is done through distancing the individuals from their positions thereby allowing for diverse perspectives and the expression of radical and conflicting opinions leads to more effective decisionmaking(Doz \& Kosonen 2008, Lewis et al 2014). Doz and Kosonen (2010) believe that "leadership unity hinges on the ability of members of the top team to understand and trust each other: several critical behaviours can enable the buildup of trust in the whole top team". This behaviours include (a) Dialoguing as against argumentative and political power tussles in order to create commitment to decisions, (b) Revealing which allows members express their concerns as well as accept collaborations that enable better business models, (c) Integrating interdependencies between businesses which may reveal hidden opportunities, (d) Aligning interests and (e) Caring thereby creating a sense of belonging and trust among team members.

This paper seeks to examine the effect of leadership unity and organizational competitiveness of deposit money banks of South South Nigeria. The paper narrows focus from strategic agility as a whole to an in-depth look at leadership unity in building competitive organizations. Thus the need for enabling leadership unity to create more agile firms and enhance and sustain competitiveness cannot be overemphasized. In this vein, the study specifically

i. Determines the relationship between leadership unity and innovativeness.

ii. Investigate the relationship between leadership unity and service quality.

iii. Examine the relationship between leadership unity and delivery reliability.

\section{RESEARCH QUESTIONS}

The study seeks to address the following questions

i. What is the relationship between leadership unity and service quality?

ii. What is the relationship between leadership unity and delivery reliability?

iii. What is the relationship between leadership unity and innovativeness?

\section{LITERATURE REVIEW The theory of Dynamic Capabilities}

The theory of dynamic capabilities advances a position on the need for organizations to consistently align their resources and capacities in line with the changes and evolving features of their environment. Panos (2013) described dynamic capabilities as the organizations fluidity in terms of knowledge and competence, and its ability to match such with the requirements and gaps of apparent in its environment. The theory provides a basis for understanding the interaction between leadership unity and organizational competitiveness in the sense that it anchors the organizations capacity development on its leader's ability to be open minded and dialogue about decisions. Thus, the competitiveness of the organization builds on this ability to effectively address and satisfy latent satisfaction gaps within its context through such learning. Chang, Lin, Yang and Sheu (2003) argued that the dynamic capabilities theory approaches the concept of change and development from a learning perspective, which according to him, emphasizes on organizations identification of key factors that offer them opportunities for relevance and innovation. 


\section{Leadership Unity}

Leadership unity involves the effective use of proper language and dialogue in creating trust as well as enabling commitment and engagement in organizations. Brannen and Doz (2012) opined that leadership unity hinges on cabinet responsibility, top team collaboration, leadership style and capabilities of the CEO. Thus in enabling leadership unity, top management are faced with the dilemma of reconciling laid down principles with business realities, promoting devolved responsibilities, ensuring intellectual cooperation between team members and incorporating a leadership style that gives room for open dialogue and collective decision making. According to Doz \& Kosonen 2010), 'business model changes often involve gut wrenching decisions for executives, calling for difficult and risky personal adjustments and collective commitments, and as such, new adaptive leadership work and leadership team unity are essential to enable shifts in business models'. In other words, the successful implementation of any model or decision hinges on the effective leadership unity. Literature has buttressed the need for a unified leadership for enabling strategic agility, though with different terminologies. While Hamel 2012 used "collective commitment" in describing leadership unity toward the successful implementation of decisions, Odja (2008) identified shared responsibility of leaders as a key to strategic agility. In the same vein, Implement Consulting Group (2013) also describes unity of leadership as one of their four dimensional concept of strategic agility.

\section{Organisational Competitiveness}

The notion of competitiveness lies at the heart of business strategy development, its definition is often vague and does not lend itself to a measurement process. Competitiveness is common place and it determines the success or failure of any business. "To achieve it requires setting priorities, which can be defined as a set of options of varying importance that a firm needs to have to compete in the market over a determined time frame" (Santos, Pires \& Gonçalves, 1999). The exploration of organisation competitiveness factors is important to achieve the most suitable method for developing products and processes, with the use of the best practices and at the lowest possible costs, to make high quality products and get them to market quickly so as to satisfy consumers' needs. According to Riley (2012) traditionally, competitiveness may be measured in monetary or non-monetary terms. A typical example to identify a competitive business includes control over distribution medium, higher sales and revenue within the industry, increased profit margin among competitors', better returns on investment etc. According to Rosenzweig et al (2003), organisational competitiveness can be measured using this area of capabilities- product quality, delivery reliability, cost leadership and process flexibility. In same vein, Roman et al (2012) suggested different measures of business competitiveness to include: "strategic alliances, human capital, reliability, knowledge, cost, cultural factors, flexibility, innovation, quality, speed, customer relations, social responsibility, control systems, production techniques and information and communication technologies". However, this study uses innovativeness, service quality and delivery reliability as measures of organizational competitiveness.

\section{Leadership Unity and Organisational Competitiveness}

Doz \& Kosonen (2010) is of the opinion that building, renewing and accelerating successful business models that ensure competitive advantage is hinged upon the leadership unity. They also opined that core behavior that ensure leadership unity includes dialoguing, revealing, integrating, aligning interest and caring among team members (doz\& Kosonen 2010, Brannen \& Doz 2012). In the same vein, Mavegenre(2013) describes leadership unity competence as a essential capability in the competitive business environment. In other words, leadership unity enables the coordination of imperative competencies, and integrates management of organizational processes and resources that in turn promotes competitive advantage of firms. Enabling and sustaining organizational competitiveness is as a result of various factors, however for the purpose of this work, organisational competitive outcomes are service quality, delivery reliability and innovativeness. 


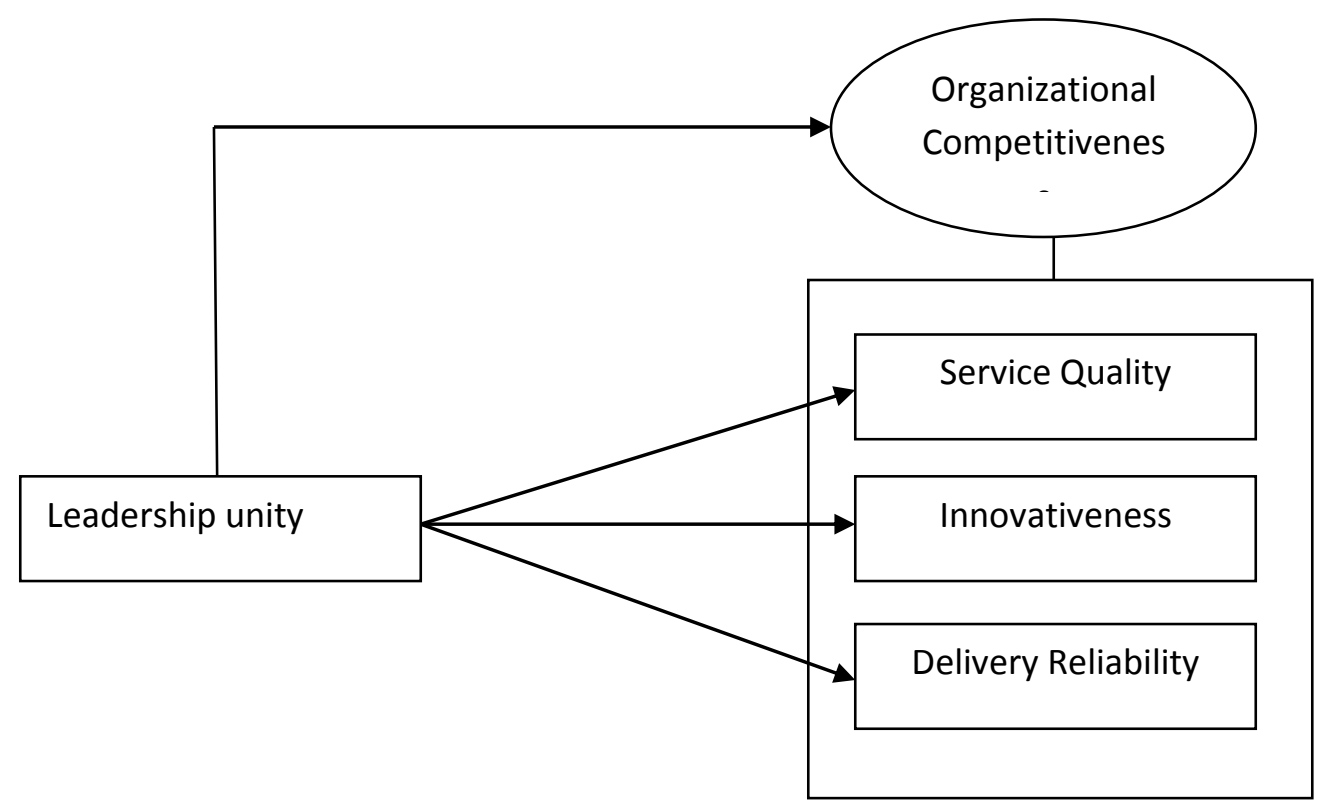

Figure 1: Operationalized framework for leadership unity and organizational competitiveness

\section{METHODOLOGY}

The study adopted the cross sectional research design adopted. The accessible population for the study is 266 senior staff of 18 deposit money banks in South South Nigeria (Bayelsa, Rivers, Cross River, Akwaibom, Delta and Edo states). Given the size (where $\mathrm{n}<500$ ) of the population, the entire 266 staff identified were adopted in the investigation, thus making the investigation a census. Data for the investigation was also generated using the questionnaire instrument which was personally administered to the target deposit money banks within the region. Instrumentation for the variables was based on existing studies where the items for leadership unity were sourced from Abu-Radi (2013), and the items for organizational competitiveness were also sourced from Rosenzweig (2003). Seven (7) items on the questionnaire were assessed for leadership unity, while the measures of organizational competitiveness(innovativeness, service quality and delivery reliability) all had \& items each, making a total of 21 items for organizational competitiveness.
The Cronbach alpha test was utilized in assessing the reliability for the instruments of the study.

\section{Data presentation and analysis}

This section of the paper, presented the result on the distribution for the variables and the test on their relationships. A total of 266 questionnaire copies were distributed, 221 copies were successfully retrieved. All retrieved copies were further cleaned, coded and assessed for outliers, missing values and other error issues likely to bias outcomes of the analysis. Assessment results revealed that all retrieved 221 copies were considered as admissible in the analysis of the study. The data is presented in three sections - (a) the demographic data distributions (b) the univariate data analysis, and (c) the test for the hypotheses.

\section{Descriptive statistics of demographics}

The tools utilized in this section comprised of the frequencies and percentage distributions. Data in this section are discrete and hence involved assessment of dominant categories and distributions for the sample characteristics. 


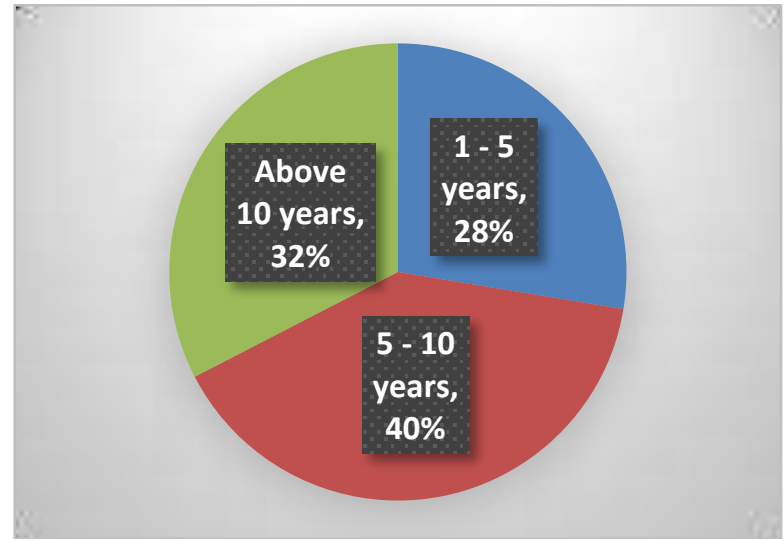

\section{Figure1 Years in the company}

Figure1 above demonstrates the distribution for the number of years respondents have spent within the companies of interest. 1-5 years had 28\%, above 10 years had $32 \%$, while $5-10$ years had $40 \%$. The distribution above shows that a more dominant category is that of the $5-10$ years. This indicates that most of the participants for this study had relevant experience due to the length of their tenure with their respective organizations.

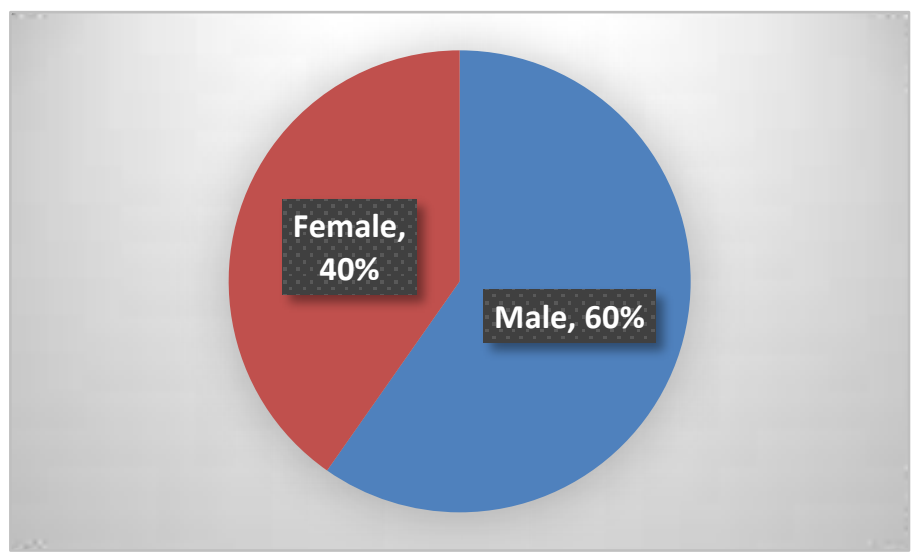

Figure 2 Gender distribution

The distribution for the gender indicates that most of the participants for the study are male where the distribution for the male category is noted to account for $60 \%$ of the total number of respondents. This shows most of the organizations examined herein have a strong and dominant male workers presence. 


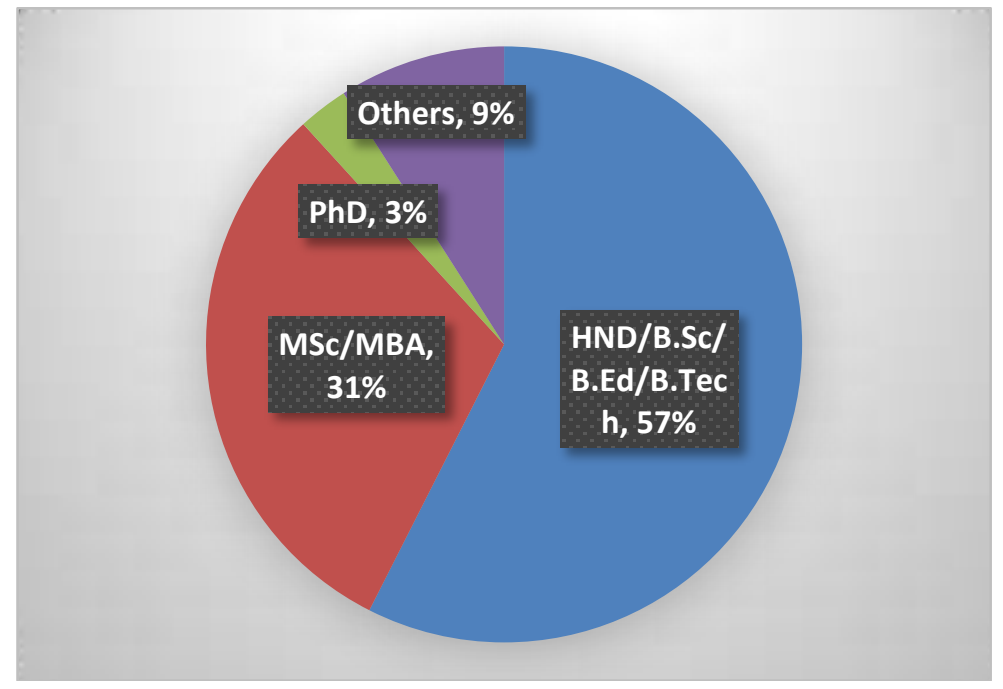

Figure 4.3 Educational qualification

The distribution for the educational distribution for the workers as demonstrated above reveals that majority of the workers have acquired diploma and first degrees, accounting for $57 \%$ of the total number of participants; this suggests that a substantial number of the participants are substantially literate given their status as graduates.

\section{UNIVARIATE DATA ANALYSIS}

Table 1: Descriptive for variables of the study

\begin{tabular}{|c|c|c|c|c|c|c|c|}
\hline & $\mathbf{N}$ & Mean & $\begin{array}{c}\text { Std. } \\
\text { Deviation }\end{array}$ & \multicolumn{2}{|c|}{ Skewness } & \multicolumn{2}{c|}{ Kurtosis } \\
\cline { 2 - 8 } & Statistic & Statistic & Statistic & Statistic & Std. Error & Statistic & Std. Error \\
\hline Leadership unity & 221 & 2.3562 & .35089 & -.517 & .164 & .098 & .326 \\
Innovativeness & 221 & 2.6846 & .49020 & .145 & .164 & 2.563 & .326 \\
Service Quality & 221 & 2.2482 & .52795 & -1.377 & .164 & .727 & .326 \\
Delivery Reliability & 221 & 2.7033 & .52469 & .628 & .164 & 3.281 & .326 \\
Valid N (listwise) & 221 & & & & & & \\
\hline
\end{tabular}

Source: survey data 2021

The table above demonstrates the distribution for the measures of organizational competitiveness (innovativeness, service quality and delivery reliability) and leadership unity. The table shows evidence which supports the delivery reliability as having the strongest and most evident manifestation within the framework and context of the study. This shows majority of the cases identify their organizations as expressing substantial levels of delivery reliability compared to the distributions for other variables. However, the result indicates that all variables are noted to be substantially reflected, this implies that the construct under study are significantly being practiced in the deposit money banks used by the researcher. 
Test of Hypothesis

\begin{tabular}{|c|c|c|c|c|c|c|}
\hline & & & Leadership & Innovative & Service & Delivery \\
\hline Spearman's rho & Innovative & $\begin{array}{l}\text { Correlation Coefficient } \\
\text { Sig. (2-tailed) } \\
\mathrm{N} \\
\text { Correlation Coefficient } \\
\text { Sig. (2-tailed) } \\
\mathrm{N} \\
\text { Correlation Coefficient } \\
\text { Sig. (2-tailed) } \\
\mathrm{N} \\
\text { Correlation Coefficient } \\
\text { Sig. (2-tailed) } \\
\mathrm{N}\end{array}$ & $\begin{array}{c}. \\
221 \\
.351^{* *} \\
.000 \\
221 \\
.294^{* *} \\
.000 \\
221 \\
.533^{* *} \\
.000 \\
221\end{array}$ & $\begin{array}{c}.351^{* *} \\
.000 \\
221 \\
1.000 \\
. \\
221 \\
.419^{* *} \\
.000 \\
221 \\
.750^{* *} \\
.000 \\
221\end{array}$ & $\begin{array}{l}.294^{* *} \\
.000 \\
221 \\
.419^{* *} \\
.000 \\
221 \\
1.000 \\
. \\
221 \\
.233^{* *} \\
.000 \\
221\end{array}$ & $\begin{array}{l}.533^{* *} \\
.000 \\
221 \\
.750^{* *} \\
.000 \\
221 \\
.233^{* *} \\
.000 \\
221 \\
1.000 \\
. \\
221\end{array}$ \\
\hline
\end{tabular}

Source: Survey Data, 2021

The test on the test for the relationship between leadership unity and the measures of organizational competitiveness - innovativeness, service quality and delivery reliability, are all revealed to be significant. Results indicate that at a rho $=0.351$ and $\mathrm{P}=0.000$; leadership unity significantly contributes towards innovativeness; at a rho $=0.294$ and a $\mathrm{P}=0.000$, leadership unity significantly enhances service quality; and at a rho $=0.533$ and a $\mathrm{P}=0.000$; leadership unity significantly influences delivery reliability. All this basis, all previously stated hypotheses are rejected as the study reveals as follows:

i. A relationship exists leadership unity and innovativeness and it is significant.

ii. A significant relationship exists between leadership unity and delivery reliability.

iii. There is a significant relationship between leadership unity and service quality.

\section{DISCUSSION ON FINDINGS}

Leadership unity significantly enhances outcomes of organizational competitiveness: The finding demonstrated a significant relationship exists between leadership unit and organizational competitiveness. Evidence from the test indicates that leadership unity positively influences outcomes of innovativeness, service quality and delivery reliability. The result indicates that top management team accepts the need for change and their capabilities in implementing any needed change speedily. This is in line with Orojloo, Feizi \& Najafabadi (2016) that states that "when the leadership of the organization is ready to change, it perceives the need to change and is sure about its ability for management of change, it is imperative that there is a shared understanding and alignment of values for success". Competitiveness suggests change in terms of openness towards innovation, improved quality and delivery reliability - and this occurs only if senior managers recognize the need to change and are committed to support in case of changes.

Therefore, the unity or cohesion of between top level managers, uniqueness promotes better decision making, individual capacity and consciousness also improve on organisational functions and features are synergized to encourage employees to support and align with leadership for effective change. Thus, the staff of any enterprise that share the goal of increased competitiveness ensure that they remodel and revamp behavioural and structural process to accommodate any disruption in the business environment. Armenakis et al. (2002) state "how there is resistance to change when there is strong disparity between leadership about measures to be adopted or platforms to be utilized". This is as a result of the perception of reduced individual consciousness and capacity of works that are averse to adapting to the changes in the environment (Odja 2008).

Thus, leadership unity is an imperative for today's organization as it aligns organizational values and repositions the organization for success. The drive and competitiveness "of an organization that is ready to change are higher than an organization that is not ready to change and the organization that is ready to change can adapt to the change" (Orojloo et al 2016) and as such offer higher competitive outcomes. 


\section{CONCLUSION}

This study identified leadership unity as a significant predictor of organizational competitiveness; Leadership unity offers cooperation and support from leadership units in innovative actions as such advances the competitiveness of the organization and leads to outcomes such as innovativeness, service quality and delivery reliability. This lends theoretical and empirical credence to the positions of previous studies (Mavengere 2013; Doz \& Kosonen 2010; Branen \& Doz 2012) who emphasize on the dynamics of the environment and the need for behavioural adaptations necessitated through leadership unity for improved levels of organizational competitiveness. . In view of the positive outcome, it is concluded that leadership unity based on its emphasis on top team collaboration, appropriate language and dialogue, empathy and care, promotes and enhances outcomes of service quality, innovativeness and delivery reliability. It is therefore recommended that organizational structures and work arrangements should be adapted to allow for stronger levels and more evident outcomes of personnel accessibility and improved communication or interaction between the leadership and co-workers within the organization in a way that drives and enhances outcomes of cohesion and unity amongst management and subordinates.

\section{REFERENCES}

1. Abu-Radi, S. (2013) Strategic Agility and Its Impact on the Operations Competitive Capabilities in Jordanian Private Hospitals ( Unpublished Thesis), Middle East University.

2. Armenakis, A. A. \& Harris, S. G.(2002) Crafting a Change Message to Create Transformational Readiness. Journal of Organisational Change Management.

3. Brannen, M. Y., \& Doz, Y. (2012). Corporate languages and strategic agility: Trapped in your jargon or lost in translation? California Management Review, 54, 77-97.

4. Chang, S.-C., Lin, N.-P., Yang, C.-L. and Sheu, C. (2003) Quality dimensions, capabilities and business strategy: An empirical study in high-tech industry. Total Quality Management, 14(4), 407421

5. Doz, Y. L., \& Kosonen, M. (2010). Embedding strategic agility: A leadership agenda for accelerating business model renewal. Long range planning, 43(2-3), 370-382.

6. Doz, Y., \& Kosonen, M. (2008). The dynamics of strategic agility: Nokia's rollercoaster experience. California Management Review, 50(3), 95-118.

7. Hamel. G, (2012). What Matters Now. Strategic Direction.28(9)

8. Implement Consulting Group. (2013). Strategic agility: What does it take to.
9. Lewis, M. W., Andriopoulos, C., \& Smith, W. K. (2014). Paradoxical leadership to enable strategic agility. California Management Review, 56(3), 5877.

10. Mavengere, N. B. (2013a). Information technology role in supply chain's strategic agility. International Journal of Agile Systems and Management, 6(1), 7-24.

11. Mavengere, N. B. (2013b). Role of information systems for strategic agility in supply chain setting: Telecommunication industry study. Electronic Journal of Information Systems Evaluation, 16(4), 327.

12. Ojha, D. (2008). Impact of strategic agility on capabilities and financial performance (unpublished doctoral Dissertation). School of Clemson University, South Carolina, United States.

13. Panos, C. (2013). The failure of foresight in crisis management: A secondary analysis of the Mari disaster, Technological Forecasting \& Social Change, 80 (9): 1657-1673

14. Riley, J., (2012), Measuring the Competitiveness of a Business, Business Blog www.tutor2u.net

15. Roman, D. J., Piana, J., e Leal, M.-A. S. P., de Mello, N. R., \& Erdmann, R. H. (2012). Organizational competitiveness factors. Brazilian Business Review, 9(1), 25-42.

16. Rosenzweig, E. D., Roth, A. V., \& Dean Jr, J.W. (2003). The influence of an integration strategy on competitive capabilities and business performance: an exploratory study of consumer products manufacturers. Journal of operations management, 21(4), 437-456.

17. Santos, F.C.A., Pires, S.R.I, and Goncalves, M.A.(1999) Competitive Priorities in Strategic Manufacturing Management: Case Studies. Revista de Administração de Empresas, v. 39, n. 4, p. 7884.

18. Sanusi, L. (2010). The Nigerian Banking Industry: what went wrong and the way forward. Delivered at Annual Convocation Ceremony of Bayero University, Kano held on, 3(1), 2010.

19. Yusuf, Y. Y., Sarhadi, M. and Gunasekaran, (1999) Agile Manufacturing: The Drivers, Concepts and Attributes, International Journal of Production Economics, 62, 33-43 